\title{
KABLO İLE SÜRÜLEN DÜZLEMSEL PARALEL BİR ROBOTUN İLERİ KİNEMATİK ÇÖZÜMÜ VE DENETIMI
}

\author{
${ }^{1}$ Caner SANCAK(D), ${ }^{2}$ Fatma YAMAÇ ${ }^{(0)}$, ${ }^{1}$ Mehmet İTIK \\ ${ }^{1}$ Karadeniz Teknik Üniversitesi, Mühendislik Fakültesi, Makine Mühendisliği Bölümü, Trabzon, TÜRKİYE \\ ${ }^{2}$ Tarsus Üniversitesi, Teknoloji Fakültesi, Otomotiv Mühendisliği Bölümü, Mersin, TÜRKİYE \\ ${ }^{1}$ csancak@ktu.edu.tr, 2 fatmayamac@tarsus.edu.tr, 1 mitik@ktu.edu.tr
}

(Geliş/Received: 30.09.2019; Kabul/Accepted in Revised Form: 01.11.2019)

ÖZ: Bu çalışmada, dört kablo ile sürülen, üç serbestlik dereceli düzlemsel bir paralel robotun hassas konum ve yönelim denetimi yapılmıştır. Kablo ile sürülen robotun geri beslemeli denetimi için gerekli olan durum değişkenleri, robotun ileri kinematik denklemlerinin çözülmesi ile elde edilmiştir. İleri kinematik denklemlerinin çözüm doğruluğunu artırmak ve yakınsama zamanını azaltmak için Yapay Sinir Ağları (YSA) ve Newton-Raphson yönteminin karma şekilde kullanıldığı bir yöntem kullanılmıştır. Bu karma yöntemde ilk olarak YSA ile bir başlangıç ileri kinematik çözüm elde edilmektedir. Elde edilen bu çözüm Newton-Raphson yönteminde başlangıç koşulu olarak kullanılarak, hem çözüme hızlı yakınsama sağlanmakta hem de sayısal çözümün doğruluğu artırılmaktadır. Ayrıca karma yöntem Newton-Raphson yönteminde başlangıç koşullarının kötü seçiminden meydana gelebilecek ıraksamaların önüne geçmektedir. Yapılan benzetim çalışmalarında, karma yöntem ile elde edilen ileri kinematik denklemlerinin gerçek zamanlı çözümleri robotun konumunu ve yönelimini denetlemek için tasarlanan kayan kipli denetleyicice geri besleme sinyali olarak kullanılmıştır. Elde edilen sonuçlar, birlikte kullanılan yöntemlerin kablo ile sürülen düzlemsel paralel robotun hassas denetiminde başarı sağlandığını göstermektedir.

Anahtar Kelimeler: Kablo ile sürülen paralel robot; Yapay sinir ă̆larl; Kayan kipli denetim, Newton-Raphson yöntemi

\section{Forward Kinematics and Control of a Planar Cable Driven Parallel Robot}

\begin{abstract}
In this study, precise position and orientation control of a planar parallel robot, driven by four cables, with three degrees of freedom was performed. The state variables required for the feedback control of the cable-driven robot were obtained by solving the forward kinematic equations of the robot. In order to increase the accuracy of the solution of forward kinematic equations and to reduce the convergence time, a method which is used in combination with Artificial Neural Networks (ANNs) and Newton-Raphson method has been used. In this mixed method, an initial forward kinematics solution is obtained by ANNs. This solution is then used as the initial condition in the Newton-Raphson method, providing fast convergence and increased accuracy of the numerical solution. Furthermore, the hybrid method prevents divergences in the Newton-Raphson method which may be caused by the poorly selected initial conditions. In the simulations, the real-time solutions of the forward kinematic equations obtained by the hybrid method were used as feedback signals to the sliding-mode controller designed to control the position and orientation of the robot. The results show that the methods used in combination have been succesful in precise control of the pose of cable driven parallel robot.
\end{abstract}

Key Words: Cable-driven parallel robot; Neural network; Sliding mode control, Newton-Raphson method 


\section{GİRIŞ (INTRODUCTION)}

Paralel bir eyleyici (manipulator), uç işlemcinin (end effector) birkaç ayrı kinematik zincirle sabit zemine bağlandığı bir kapalı döngü kinematik zincir mekanizmasıdır (Merlet 1999). Kablo ile Sürülen Paralel Robotlar (KSPR'ler) ise, uç işlemcinin birden fazla kablo ile paralel olarak desteklendiği ve kabloların uzunluklarının eyletici (aktüator) yardımı ile değiştirilerek hareketin sağlandığı bir tür paralel eyleyicidir. KSPR'ler, basit ve hafif mekanik yapısı, büyük çalışma alanları, birimsel (modular) geometrileri, kolay taşınabilirlikleri ve yüksek hızlarda hareket edebilme gibi özellikleri ile geleneksel paralel robotlara göre birçok avantaja sahiptirler. Bu özelliklerden dolayı, KSPR'ler malzeme taşıma ve yerleştirme, tıbbi uygulamalarda rehabilitasyon cihazları, oyun simülatörleri ve endüstriyel uygulamalar gibi birçok alanda kullanılabilmektedirler (Gosselin 2014).

KSPR'lerin uygulamalar için birçok avantajının olmasına rağmen, paralel yapısı, kabloların sadece çekme kabiliyetinin olması ve dolayısıyla itme kuvveti uygulayamaması bu tip robotların analizinde, tasarımında, denetiminde ve pratik uygulamalarında bazı sorunlar ortaya çıkarmaktadır. Bu sorunlardan biri, kablo uzunlukları verildiğinde robotun konum ve yönelimini (oryantasyon) bulmak için kullanılan ileri kinematik problemin çözümüdür. Doğrusal olmayan ileri kinematik denklemlerinin çözümü genellikle birden fazla çözümle sonuçlandığı için tek ve doğru çözüm üretmek zordur. İleri kinematik problemini çözmek için analitik yaklaşımlar ve sayısal yöntemler bulunmasının yanı sıra, uç işlemcinin konumunu anlık olarak veren sensörlerin kullanımı gibi çeşitli yöntemler mevcuttur. Analitik yöntemler çok basit denklemlerin çözümünde kullanıldığı için çok kablolu ve serbestlik derecesi yüksek sistemlerin çözümünde kullanılmaları mümkün olmamaktadır (Bosscher ve diğ., 2007). Sayısal yöntemlerde ise doğrusal olmayan ileri kinematik denklemlerin çözümü temel olarak Newton-Raphson yöntemi gibi yöntemlere dayanmaktadır (Jeong ve diğ., 1999). Sayısal yöntemler ile çözümlemede iyi bir başlangıç koşulu olmadan çözümünün yapılması her zaman kesin bir çözümü garanti etmemekte ve bu tür yöntemlerin yakınsamaları büyük oranda uygun başlangıç koşullarının seçimine bağlı olmaktadır.

Geleneksel yöntemlere ek olarak, ileri kinematik problemini çözmek için Yapay Sinir Ağları (YSA) da kullanılmaktadır (Ghasemi ve diğ., 2010). Ayrıca, birkaç farklı yöntemin özelliklerinden faydalanmak için karma (hybrid) yöntemler de geliştirilmiştir (Pott 2010). Bu yöntemlere örnek olarak YSA ve Levenberg-Marquardt (Schmidt 2014) ile Tetrahedron ve Levenberg-Marquardt (Lv 2017) verilebilir. Karma yöntemlerinin yakınsama doğruluğunu artırmak için sayısal en iyileme de (optimization) uygulanmıştır (Pott 2015). Uç işlemci konumunun belirlenmesinde diğer olası yaklaşımlar ise konumun doğrudan görüntülenmesi veya lazer sensör tabanlı sistemler tarafından elde edilmesi şeklindedir (Lytle 2004, Bayani ve diğ., 2016, Sancak 2018). Ancak, bu sistemler oldukça maliyetlidir ve görüntü tabanlı sistemlerin doğruluğu doku, malzeme ve ışık koşullarından kolayca etkilenebilmektedir.

Literatürde KSPR'leri denetlemek için uygulanan farklı denetim yöntemleri bulunmaktadır. KSPR'lerin denetimi için ilk olarak PD (Proportional-Derivative) denetleyicisi ile hesaplamalı tork yöntemi beraber uygulanmıştır (Williams 2003). KSPR'ler yüksek derecede bağlaşık (coupled) ve doğrusal olmayan dinamik sistemler olduğundan, denetiminde daha iyi sonuçlar elde etmek için daha gelişmiş denetim yöntemlerine ihtiyaç vardır. Bu yüzden bu tip robotların denetimi için uyarlanabilir, gürbüz ve doğrusal olmayan denetçiler önerilmiştir (Oh 2004, Khosravi ve Taghirad 2014, Bayani ve diğ., 2016). Robotun geri beslemeli denetimi için kablo uzunluklarının ölçülmesi, uç işlemcinin konum ve yöneliminin elde edilmesinde ileri kinematik çözümü gerekli kılarak ek bir sorun ortaya çıkartmaktadır. Bu sorunun en iyi şekilde çözülmesinde karma yöntemler gerçek zamanlı uygulamalar için yüksek doğruluk ve hızlı sonuç sağlayabilmektedir. Bu kapsamda, robotun konumunu denetlemek için ileri kinematik denklemlerinin gerçek zamanlı çözümleri karma yöntemlerle yapılarak, denetçiye geri besleme sinyali olarak kullanılmıştır (Khosravi ve Taghirad, 2014, Lv ve diğ., 2017).

$\mathrm{Bu}$ çalışmada, dört kablo ile sürülen ve zemine dik düzlemde hareket eden kablolu paralel bir robotun ileri kinematik problemini çözmek için YSA ve Newton-Raphson yönteminden oluşan karma bir yöntem kullanılmıştır. Bu karma yöntemdeki amaç, YSA kullanarak ileri kinematik problem için yaklaşık bir çözüm elde etmek ve daha sonra bu çözümü iyi başlangıç koşulları ile hızlı sonuç veren Newton-Raphson algoritmasına başlangıç koşulu olarak kullanmaktır (Parikh ve Lam, 2005). Böylelikle 
çözümün iyileştirilmesi, hızlandırılması ve dolayısıyla gerçek zamanlı uygulamalarda kullanıma uygun olması sağlanmaktadır. Belirtilen yöntem Gough-Stewart platformuna uygulanmış ve başarılı sonuçlar elde edilmiştir (Parikh ve Lam, 2005). Bu yöntem ile ileri kinematik çözümden elde edilen konum ve yönelim bilgisi, KSPR'nin denetimi için geri besleme sinyali olarak kullanılmıştır. Böylelikle kamera yardımı ile uç eyleyicinin konumunu ve yönelimini görüntü işleme ile elde etmede karşılaşılacak yüksek donanım maliyeti ve işlemci gücü ihtiyacından tasarruf edilmesi hedeflenmiştir. Denetleyici olarak belirsizliklere ve bozuculara karşı gürbüz bir denetim yöntemi olan kayan kipli denetleyici tasarlanmış ve bu denetleyici, ileri kinematik çözümün geri besleme olarak kullanıldığı benzetim ortamında uygulanmıştır. Bu çalışma ile birlikte, kablo ile sürülen düzlemsel bir robotun hassas konum ve yönelim denetiminde gerçek zamanlı olarak kullanılabilecek bir yöntemler bütünü önerilmiştir.

Çalışmanın ana hatları şu şekilde verilmektedir. İlk olarak kablo ile sürülen paralel robotun kinematik ve dinamik analizi ele alınmıştır. Ardından Kayan Kipli Denetim tasarımı açıklanmıştır. Sonraki bölümde ise sistemin benzetiminde izlenen yol ve benzetim sonuçları verilmiş olup, son olarak yapılan çalışmalardan elde edilen sonuçlar irdelenmiştir.

\section{KABLO İLE SÜRÜLEN PARALEL ROBOT (CABLE-DRIVEN PARALLEL ROBOT)}

$\mathrm{Bu}$ çalışmada ele alınan KSPR basit olarak sabit bir ana çerçevenin köşelerine yerleştirilmiş eyleticiler tarafından uzunluğu değiştirilen dört kablo yardımı ile paralel olarak desteklenmiş ve bir uç işlemci görevi yapan gövdeden oluşmaktadır. Şekil 1, KSPR'nin kinematik diyagramını göstermektedir.

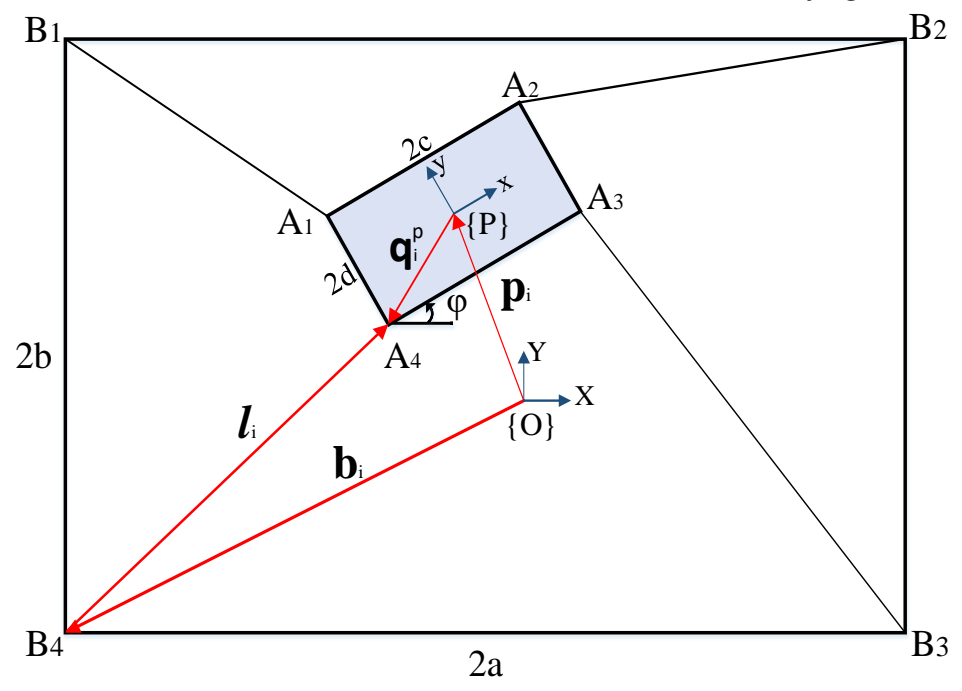

Şekil 1. KSPR'nin kinematik diyagramı

Figure 1. Kinematics diagram of $C D P R$

Robota ait ana çerçevenin ortasındaki $\{O\}$ sabit referans noktasında bulunan X-Y koordinat sistemi ve hareketli uç işlemcinin ağırlık merkezindeki $\{\mathrm{P}\}$ referans noktasında bulunan $\mathrm{x}$-y koordinat sistemi olmak üzere iki koordinat sistemi bulunmaktadır. Kabloların bir ucu $\mathrm{A}_{1}, \mathrm{~A}_{2}$, $\mathrm{A}_{3}$ ve $\mathrm{A}_{4}$ noktalarından uç işlemciye, diğer ucu ise $\mathrm{B}_{1}, \mathrm{~B}_{2}$, $\mathrm{B}_{3}$ ve $\mathrm{B}_{4}$ noktalarından eyleticilere bağlıdır. Burada $\boldsymbol{l}_{i}$ kablo uzunlukları, $\boldsymbol{b}_{i}$ ana çerçevenin merkezi ile köşeleri arası mesafe, $\boldsymbol{q}_{i}$ uç işlemcinin merkezi ile köşeleri arasındaki mesafe, $\mathbf{R}$ dönme matrisi, $\mathbf{p}$ uç işlemcinin $\{O\}$ sabit referans noktasına göre konumu ve $\phi$ uç işlemcinin $\{O\}$ referans noktasına göre dönme açısıdır.

\section{KSPR'nin Kinematiği (Kinematics of Cable Driven Parallel Robot)}

$\mathrm{Bu}$ çalışmada ele alınan KSPR genel bir yapıya sahip olup ters ve ileri kinematik denklemleri kolayca elde edilebilmektedir (Vadia 2003). Ters kinematik analitik olarak nispeten kolayca çözülmesine karşın ileri kinematik çözüm artıksıl (redundant) eyletmeden dolayı zor olmaktadır. Kabloların sadece gerilim taşıyabilmesi nedeniyle artıksıl eyletme gerekli olmaktadır. 


\section{Ters Kinematik (Inverse Kinematics)}

KSPR için ters kinematik, uç işlemcinin konumunun ve yöneliminin verilmesi durumunda gerekli kablo uzunluklarının bulunması işlemidir. KSPR'nin ters kinematiği, her bir kablo için bir kapalı döngü kinematik zinciri kullanılarak modellenmiştir. Uç işlemcinin p konumu ve iki koordinat sistemi arasındaki yönelim matrisi $\mathbf{R}$ bilindiği durumda kablo uzunlukları Denklem (1) ile hesaplanır;

$\mathbf{l}_{i}=\mathbf{p}+\mathbf{R} \mathbf{q}_{i}^{p}-\mathbf{b}_{i}$

Denklem (1) açık olarak yazılırsa;

$l_{i}=\sqrt{\left(x-b_{i x}+q_{i x}^{p} \cos \varphi-q_{i y}^{p} \sin \varphi\right)^{2}+\left(y-b_{i y}+q_{i x}^{p} \sin \varphi+q_{i y}^{p} \cos \varphi\right)^{2}}$

burada $\mathbf{p}=\left[\begin{array}{l}x \\ y\end{array}\right]$ ve $\mathbf{R}=\left[\begin{array}{cc}\cos \varphi & -\sin \varphi \\ \sin \varphi & \cos \varphi\end{array}\right]$ 'dır.

\section{İleri Kinematik (Forward Kinematics)}

KSPR'ler için ileri kinematik problem; kablo uzunluklarını ölçülmesi ve bu uzunlukların vektör kapalılık denklemlerinde kullanılması ile uç işlemcinin gerçek konumunun belirlemesi işlemidir. Dört kablo ile sürülen robotun ileri kinematiğine bakıldığında denklem sayısının bilinmeyen sayısından çok olduğu doğrusal olmayan bir denklem sistemi görülmektedir. Bu doğrusal olmayan denklemleri çözmek zordur, çünkü bağlaşık doğrusal olmayan denklemlerin çözümünü gerektirir ve genellikle birden fazla çözümle sonuçlanır. Analitik yaklaşımlar, sayısal yöntemler ve algılayıcılar yardımıyla bu problem çözülebilir. Ancak analitik teknikler bazı geometrik basitleştirmeler gerektirir, sayısal yöntemler ise uygun başlangıç koşullarının seçimine dayanır ve algılayıcıların kullanımı pahalı olabilmektedir. Bu sebeple, yapılan çalışmada ileri kinematik denklemlerini çözmek için Yapay Sinir Ağları ve Newton-Raphson yöntemini birleştiren karma bir yöntem kullanılmıştır.

\section{Yapay Sinir Ağları Tasarımı (Neural Networks Design)}

Oluşturulacak olan ileri kinematik YSA modeli, kablo uzunlukları verildiğinde uç işlemcinin konum ve yönelim açısını bulmak için kullanılacaktır. Bu model için gerekli veri seti elde edilirken Şekil 2a'da kesikli çizgi ile gösterilen çalışma alanı içerisindeki çok sayıda (yaklaşık 4776013 adet) nokta ve açı değerleri için ters kinematik denklem çözülerek $\{x, y\}$ konumu ile $\{\phi\}$ açı değerlerine karşılık $1_{1}, 1_{2}, 1_{3}, 1_{4}$ kablo uzunlukları hesaplanmıştır. Elde edilen bu veriler ile girişler $1_{1}, 1_{2}, 1_{3}$, ve $1_{4}$ kablo uzunlukları ve çıkışlar ise $\{x, y\}$ konumu ile $\{\phi\}$ açısı olacak şekilde YSA modelinin yapısı oluşturulmuş ve doğru bir sonuç verecek şekilde uygun ağ yapısına ulaşıncaya kadar denemeler yapılmıştır. 

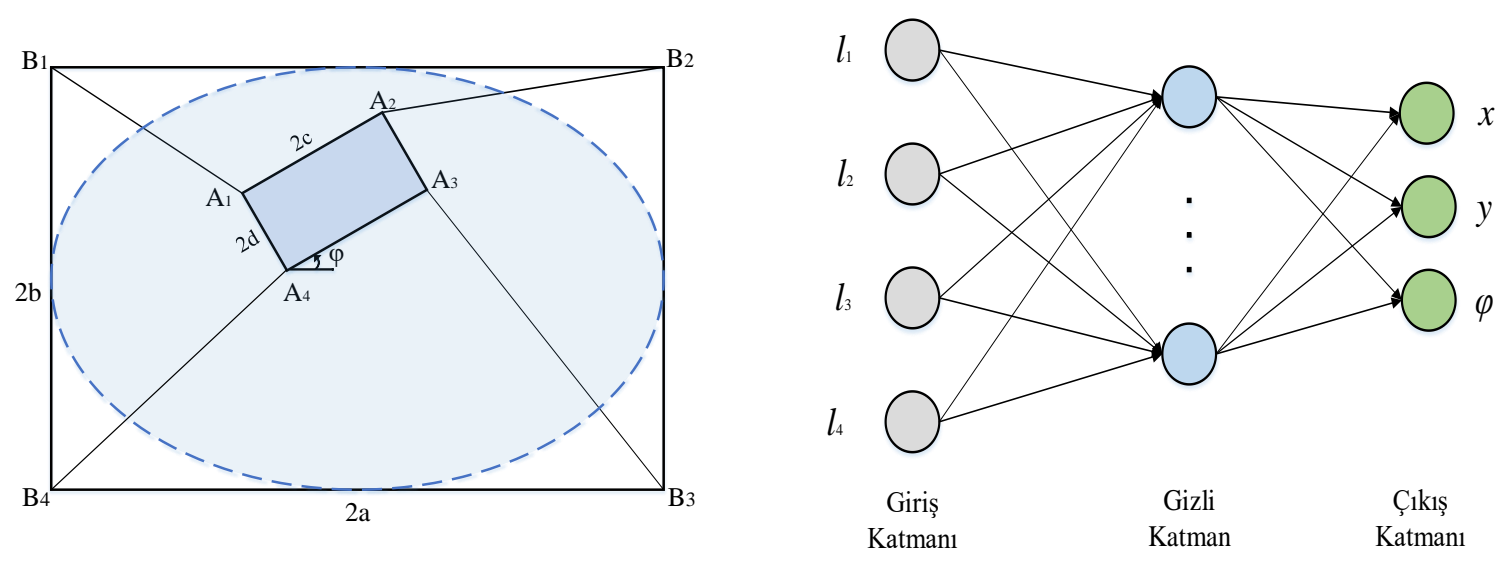

Şekil 2. a) YSA modelinin veri seti için kullanılan alan (taralı alan) b) İleri kinematik YSA modeli Figure 2. a) Workspace for ANN model data set $\boldsymbol{b}$ ) NN structure of forward kinematics

Şekil 2, KSPR'nin ileri kinematik çözümü için üretilen YSA yapısını göstermektedir. Giriş katmanı $1_{1}$, $1_{2}, 1_{3}$, ve $1_{4}$ 'ü içeren dört nörondan ve çıkış katmanı $\{\mathrm{x}$ y $\phi\}$ konumunu ve açısını ifade eden üç nörondan oluşmaktadır. Gizli katmanda ise 10 adet nöron bulunmaktadır. Sigmoid fonksiyonu, doğrusal olmayan modeller için uygun olması nedeniyle gizli katmanın aktivasyon fonksiyonu olarak kullanılmıştır. Çıkış katmanında ise Purelin aktivasyon fonksiyonu kullanılmıştır. Eğitilen YSA modeli için LevenbergMarquardt algoritması seçilmiştir. Şekil 3a ve Şekil $3 b$ de oluşturulan YSA modelinin başarımı gösterilmektedir.
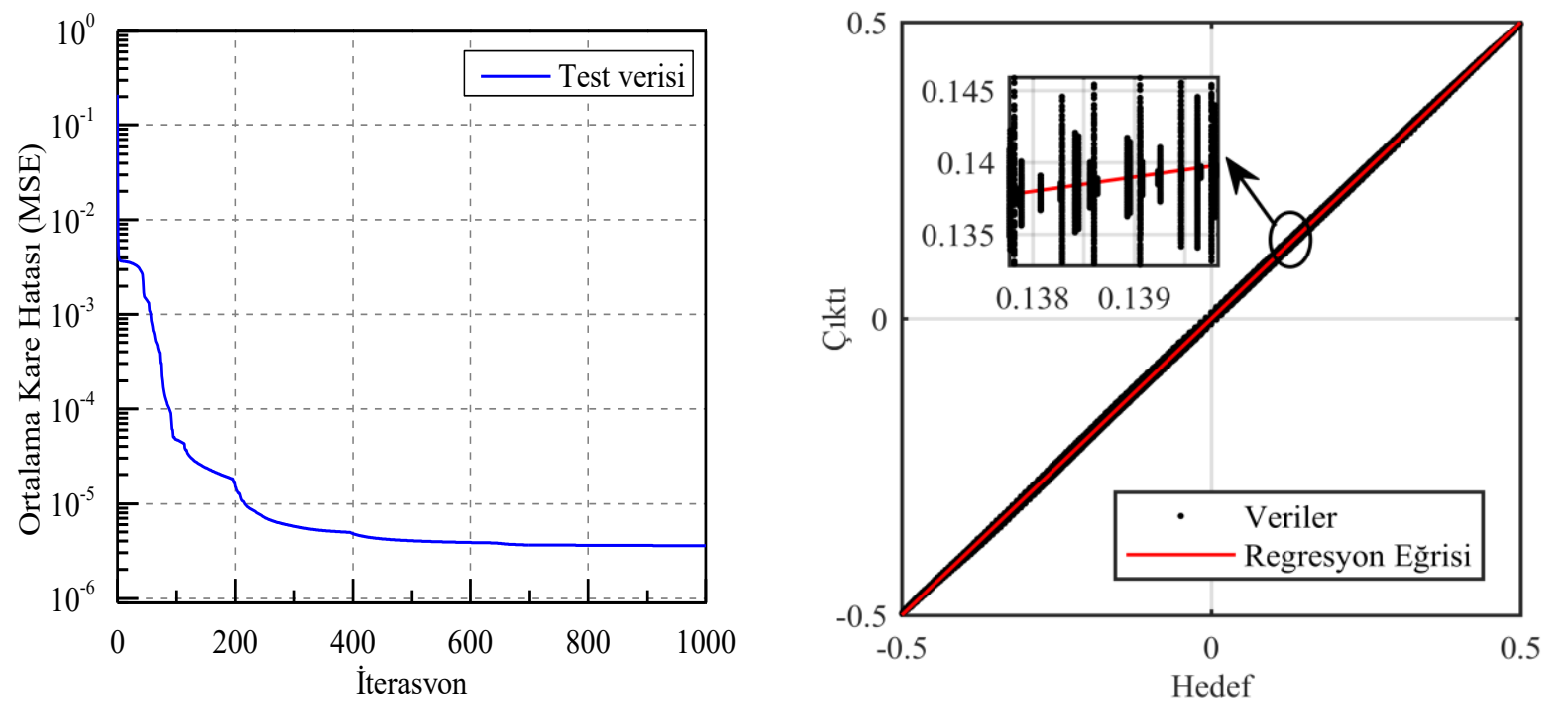

Şekil 3. a) YSA modelinin Ortalama Kare Hata (MSE)'sı (solda) b) YSA modeli regresyon eğrisi (sağda) Figure 3. a) Mean Squared Error (MSE) of ANN (left) b) Regression of NN (right)

YSA modeli ileri kinematik için iyi bir çözüm sağlamış olsa bile, daha hassas konum ve yönelim bilgisini elde etmek için Newton-Raphson yöntemiyle çözümün iyileştirilmesi sağlanmaya çalışılmıştır. Newton-Raphson yönteminin başarımı başlangıç değerlerinin seçimine bağlıdır. Başlangıç değerleri gerçek çözümden uzak olduğunda, Newton-Raphson yönteminin bir çözüme yakınsaması çok uzun zaman alabilmekte ve aynı zamanda doğru sonuca yakınsamayabilmektedir. Bu nedenle, YSA'dan elde edilen çıkışlar Newton-Raphson yönteminin hızlı ve daha iyi yakınsayarak doğru sonuçları elde etmesi için başlangıç koşulları olarak kullanılmıştır. 


\section{Newton-Raphson yöntemi (Newton Raphson Method)}

Newton-Raphson yönteminin uygulanması için Denklem 2'de verilen eşitlik aşağıdaki şekilde yeniden düzenlendiğinde;

$$
\begin{aligned}
F_{i}(X)= & x^{2}+y^{2}+q_{i x}^{p 2}+q_{i y}^{p 2}+b_{i x}{ }^{2}+b_{i y}{ }^{2}+2 x\left(q_{i x}^{p} \cos \varphi-q_{i y}^{p} \sin \varphi\right)+2 y\left(q_{i x}^{p} \sin \varphi+q_{i y}^{p} \cos \varphi\right)-\ldots \\
& 2\left(q_{i x}^{p} b_{i x}+q_{i y}^{p} b_{i y}\right) \cos \varphi+2\left(q_{i y}^{p} b_{i x}-q_{i x}^{p} b_{i y}\right) \sin \varphi-l_{i}^{2}=0
\end{aligned}
$$

YSA'dan elde edilen $\mathrm{x}$, y ve $\phi$ değerleri kullanılarak oluşturulan $X_{0}$ başlangıç koşulu ile Denklem 3 kullanılarak aşağıdaki adımlar iteratif bir şekilde takip edilir.

- $\quad J_{N R} \delta X_{k}=-F(X), \delta X_{k}$ için çözüm elde edilir.

$\delta X_{k}=-J_{N R}^{+} F(X)$

- $\quad X_{k+1}=X_{k}+\delta X_{k}$ yeni çözüm bulunur.

- $\quad\left\|\delta X_{k}\right\|<\varepsilon$ durdurma şartı kontrol edilir.

Burada $F(x)=\left\{F_{i}(X)\right\}, \delta X=\{\delta x, \delta y, \delta \varphi\}^{T}, \varepsilon$ kullanıcı tanımlı tolerans ve $J_{N R}^{+}=\left(J_{N R}^{T} J_{N R}\right)^{-1} J_{N R}^{T}$ Jacobian matrisinin pseudo inverse matrisidir. Jacobian matrisi Denklem $4^{\prime}$ te verilmiştir.

$J_{N R}=\left[\left\{\frac{\delta F_{i}}{\delta x}\right\}\left\{\frac{\delta F_{i}}{\delta y}\right\}\left\{\frac{\delta F_{i}}{\delta \varphi}\right\}\right]$

$$
\begin{aligned}
& \left\{\frac{\delta F_{i}}{\delta x}\right\}=2\left(x+q_{i x}^{p} \cos \varphi-q_{i y}^{p} \sin \varphi-b_{i x}\right) \\
& \left\{\frac{\delta F_{i}}{\delta y}\right\}=2\left(y+q_{i x}^{p} \sin \varphi+q_{i y}^{p} \cos \varphi-b_{i y}\right) \\
& \left\{\frac{\delta F_{i}}{\delta x}\right\}=2\left(q_{i x}^{p}\left[-\left(x-b_{i x}\right) \sin \varphi+\left(y-b_{i y}\right) \cos \varphi\right]+q_{i j}^{p}\left[-\left(y-b_{i y}\right) \sin \varphi-\left(x-b_{i x}\right) \cos \varphi\right]\right)
\end{aligned}
$$

\section{KSPR'nin Dinamik Yapısı ve Gerilim Dağıtım Algoritması (Dynamics of Cable Driven Parallel Robot and Torque Estimation Algorithm)}

Dinamik modelleme, uç işlemcinin hareketi için gerekli olan aktif eklem torkları ile ilgilidir. Bu yüzden KSPR'nin dinamik modelinin, eyleticiler ve uç işlemci dinamiklerinden oluştuğu varsayılmıştır. Burada eyleticiler, kabloları bir makara üzerine sararak veya bırakarak kablo uzunluğunu değiştiren motorlar olarak düşünülmektedir. Robotun dinamik modelini basitleştirmek için kablolar kütlesiz ve rijit bir eleman olarak kabul edilmiş ve kablo dinamikleri göz ardı edilmiştir. Şekil 4'te uç işlemci ve eyleticiye ait serbest cisim diyagramları gösterilen KSPR'nin genel dinamik denklemleri aşağıda verilmiştir (Williams 2003); 

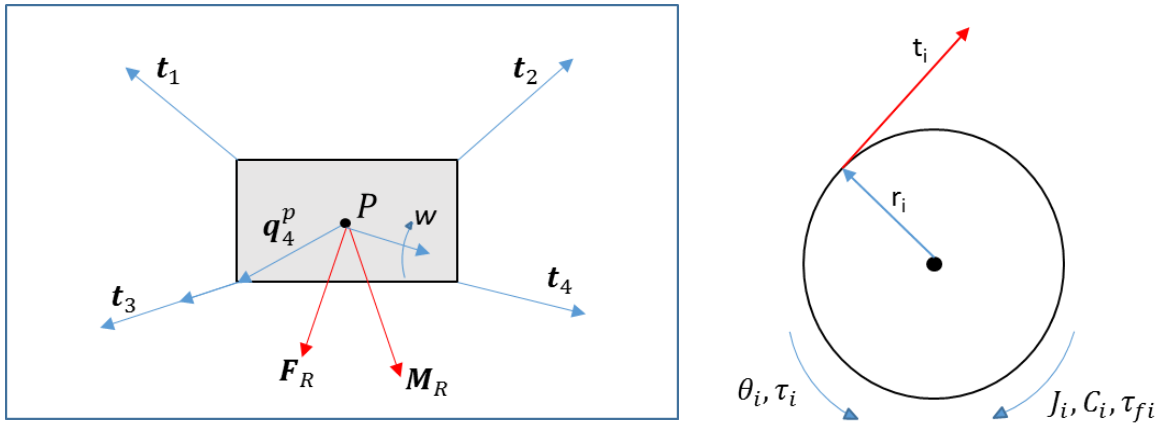

Şekil 4. a) Uç işlemci serbest cisim diyagramı (solda) b) eyletici serbest cisim diyagramı (sağda) Figure 4. a) Free body diagram of end effector (left) b) free body diagram of actuator (right)

$\mathbf{M}_{\mathrm{eq}} \mathbf{N}(\mathbf{X}, \mathbf{X})=\mathbf{S} \tau$

$\mathbf{M}_{\mathrm{eq}}=\mathbf{S} \mathbf{J}\left(\frac{\partial \boldsymbol{\theta}}{\partial \mathbf{X}}\right)+\mathbf{r}\left[\begin{array}{cc}\mathrm{m}_{\mathrm{e}} \mathbf{I}_{3 \times 3} & 0 \\ 0 & \mathbf{I}_{\mathbf{e}}\end{array}\right]$

$\mathbf{N}(\mathbf{X}, \mathbf{X})=\mathbf{S}\left(\mathbf{J} \frac{\mathrm{d}}{\mathrm{dt}}\left(\frac{\partial \boldsymbol{\theta}}{\partial \mathbf{X}}\right)+\mathbf{C}\left(\frac{\partial \boldsymbol{\theta}}{\partial \mathbf{X}}\right)\right) \mathbf{X}_{+} \mathbf{S} \boldsymbol{\tau}_{\mathrm{f}}+\mathbf{r}\left\{\begin{array}{c}-\mathrm{m}_{\mathrm{e}} \mathbf{g}-\mathbf{F}_{\mathrm{R}} \\ \boldsymbol{w} \times \boldsymbol{I}_{\boldsymbol{e}} \boldsymbol{w}-\mathbf{M}_{\mathbf{R}}\end{array}\right\}$

$\mathbf{M}_{e q}$ eşdeğer kütle matrisi, $\mathbf{X}=[x, y, \varphi]^{T}$ uç işlemci konumu ve yönelimi, $\mathbf{N}(\mathbf{X}, \dot{\mathbf{X}})$ doğrusal olmayan terimler, $S$ yapı matrisi, $\boldsymbol{\tau}=\left[\tau_{1}, \tau_{2}, \tau_{3}, \tau_{4}\right]^{T}$ eyletici giriş torku, $\boldsymbol{\tau}_{f}$ eyleticinin sürtünme torku, $\theta=$ $\left[\theta_{1}, \theta_{2}, \theta_{3}, \theta_{4}\right]$ eyleticilerin açısal konumu, $\mathbf{J}=\operatorname{diag}\left(J_{1}, J_{2}, J_{3}, J_{4}\right)$ eyletici sisteminin dönme ataleti, $\mathbf{r}=$ $\operatorname{diag}\left(r_{1}, r_{2}, r_{3}, r_{4}\right)$ kabloları saran makaranın yarıçapı, $\mathbf{C}=\operatorname{diag}\left(C_{1}, C_{2}, C_{3}, C_{4}\right)$ eyletici sisteminin sönüm katsayısı, $m_{e}$ uç işlemcinin kütlesi, $I_{e}$ uç işlemcinin kütlesel atalet momenti, $g$ yer çekimi ivmesi, $w$ uç işlemcinin merkezinin açısal hızı, $\mathbf{F}_{\mathrm{R}}$ ve $\mathbf{M}_{\mathrm{R}}$ uç işlemciye dişarıdan uygulanan kuvvet ve moment vektörleridir.

Geçerli bir kinematik ve dinamik model elde etmek için dört kablonun da pozitif gerilme kuvveti altında olması gerekmektedir. Burada sistem üç serbestlik derecesine sahiptir ve bu üç serbestlik derecesini denetlemek için dört eyletici bulunmaktadır. Sistem fazladan eyleticiye sahip olduğundan uç işlemciye gerekli kuvvet ve momenti uygulamak için kablolara uygulanabilecek sonsuz farklı gerilme vektörü $\mathbf{T}=\boldsymbol{\tau} / \mathbf{r}$ mevcuttur. Kablolara uygulanacak $\mathrm{T}$ gerilmesini bulmak için literatürde özel ve homojen çözüm olarak adlandırılan iki çözümden oluşan yaklaşımlarından faydalanılmıştır (Williams 2003, Shen 1994). Bu yöntemde gerekli kablo gerilmeleri aşağıdaki gibi verilebilir;

$\mathbf{T}=\left[\begin{array}{l}t_{1} \\ t_{2} \\ t_{3} \\ t_{4}\end{array}\right]+\alpha\left[\begin{array}{l}n_{1} \\ n_{2} \\ n_{3} \\ n_{4}\end{array}\right]$

$\alpha_{i}=\frac{\left(t_{\min }-t_{i}\right)}{n_{i}}, \quad i=1,2,3,4$ 
Burada, Denklem (8)'nın birinci terimi özel çözümü ve ikinci terimi de yapı matrisi S'nin sıfır uzay (kernel) vektörü olan homojen çözümü ifade etmektedir. Denklem (8)'daki skaler $\alpha$ parametresi Denklem (9)'in en büyük değeri olarak seçilir. Denklem (9) içerisindeki $t_{\text {min }}$ değeri küçük bir pozitif sayı olarak seçilebilir veya Denklem (10) kullanılarak KSPR'nin dinamik davranışı nedeniyle sarkma olabilecek tüm kablolarda pozitif gerilmenin korunmasını sağlayacak şekilde Denklem (11)'daki gibi $\tau_{\min }$ 'in hesaplanmasiyla bulunabilir (Vadia 2003).

$$
\begin{aligned}
& \{T\}_{i}=\left\{\frac{1}{r}\left\{\tau-\mathbf{J}\left(\frac{\mathrm{d}}{\mathrm{dt}}\left(\frac{\partial \boldsymbol{\theta}}{\partial \mathbf{X}}\right)+\frac{\partial \boldsymbol{\theta}}{\partial \mathbf{X}}\right)+\mathbf{C}\left(\frac{\partial \boldsymbol{\theta}}{\partial \mathbf{X}}\right)\right\}\right\}_{i} \geq 0 \\
& \tau_{\min }=\max \left\{\left\{\mathbf{J}\left(\frac{\mathrm{d}}{\mathrm{dt}}\left(\frac{\partial \boldsymbol{\theta}}{\partial \mathbf{X}}\right)+\frac{\partial \boldsymbol{\theta}}{\partial \mathbf{X}}\right)+\mathbf{C}\left(\frac{\partial \boldsymbol{\theta}}{\partial \mathbf{X}}\right)\right\}, 0\right\}
\end{aligned}
$$

\section{KAYAN KİPLİ DENETIM TASARIMI (SLIDING MODE CONTROLLER DESIGN)}

Bu bölümde, KSPR'nin uç işlemcisi için istenen bir yörüngeyi takip etme problemi kayan kipli denetleyici kullanarak ele alınmıştır. Öncelikle, aşağıdaki denklemlerde verildiği üzere ile bir kayma yüzeyi ve Lyapunov fonksiyonu tanımlanmıştır.

$\sigma_{3 x 1}=\&+\lambda \mathrm{e}$

$\mathbf{V}=\frac{1}{2} \boldsymbol{\sigma}^{T} \boldsymbol{\sigma}$

Burada $\lambda \in \mathrm{R}^{3 \times 3}$ pozitif tanımlı diyagonal bir matristir ve $\mathbf{e}=\mathbf{X}_{\mathrm{d}}-\mathbf{X}$ hatası takip edilmesi istenen konum $\left(\mathbf{X}_{\mathrm{d}}\right)$ ile gerçek konum $(\mathbf{X})$ arasındaki farktır. Lyapunov fonksiyonunun türevi Denklem (14) ile aşağıdaki şekilde verilmiştir.

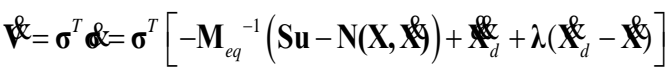

Hatanın kayma yüzeyine çekilmesi için yeterli şart $\dot{\mathbf{V}}$ ifadesinin negatif olmasıdır. Bu şartı sağlayacak $\mathbf{u}$ denetim girişi ise aşağıdaki şekilde belirlenmiştir.

$\left.\mathbf{u}=(\mathbf{S})^{-1}\left(\mathbf{M}_{e q}+\lambda \&+\mathbf{K} \operatorname{sgn}(\boldsymbol{\sigma})\right)+\mathbf{N}(\mathbf{X}, \mathbf{X})\right)$

Burada $\mathbf{K}=\operatorname{diag}\left(k_{1}, k_{2}, k_{3}\right)$ ve $\operatorname{sgn}(\boldsymbol{\sigma})=\left[\operatorname{sgn}\left(\sigma_{1}\right), \operatorname{sgn}\left(\sigma_{2}\right), \operatorname{sgn}\left(\sigma_{3}\right)\right]^{T}$ 'dir.

Denetim girişi tanımlandıktan sonra, KSPR'nin Kinematiği kısmında belirtilen gerilim dağıtım algoritması hareket sırasında kabloların sarkmasını önlemek için kullanılmıştır.

\section{BENZETIM ÇALIŞMALARI (SIMULATION RESULTS)}

Kablo ile Sürülen Paralel Robot başlı̆̆ı altında verilen KSPR modeli kullanılarak önceki bölümlerde bahsedilen karma yöntemin etkinliğini doğrulamak için benzetim çalışmaları gerçekleştirilmiştir. Karma yöntemin benzetimi MATLAB/ Simulink platformunda yapılmış ve test edilmiştir. Sisteme ait genel denetim şeması Şekil 5'te şematik olarak gösterilmektedir. Kinematik, dinamik ve denetleyici parametreleri Çizelge 1'de verilmiştir. Kinematik ve dinamik parametreler laboratuvar ortamında yapılabilecek deneysel bir çalışma göz önüne alınarak belirlenmiştir ve robota dışarıdan uygulanan bir kuvvet ve momentin olmadığı varsayılmıştır. Kayan kipli denetleyici için denetim parametreleri ise, 
çatırdama problemini göz önünde bulundurarak ve maksimum denetim girdisi olan $2 \mathrm{Nm}$ değerini aşmayacak şekilde benzetim ortamından faydalanarak belirlenmiştir.

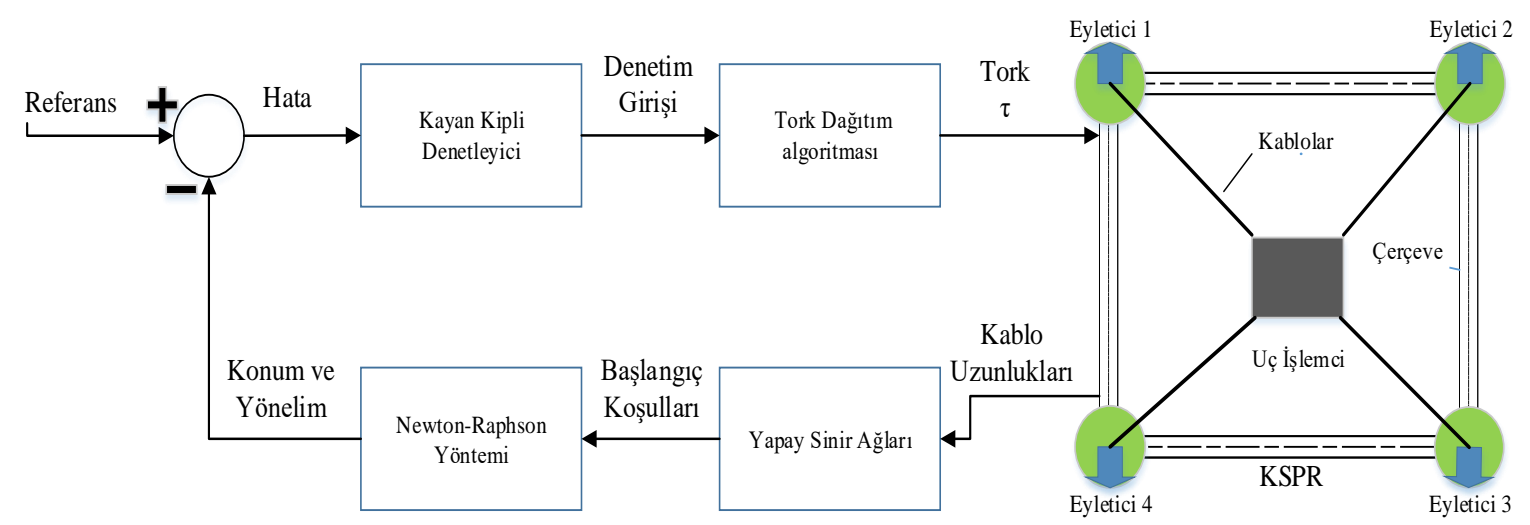

Şekil 5. KSPR sisteminin denetim şeması

Figure 5. Control scheme and CDPR system

Çizelge 1. Benzetim Parametreleri

Table 1. Simulation Parameters

\begin{tabular}{|c|c|c|c|}
\hline \multicolumn{2}{|c|}{ Denetim parametreleri } & \multicolumn{2}{c|}{ Kinematik Parametreler } \\
\hline $\boldsymbol{K}$ & $\operatorname{diag}(1.5,1.5,1)$ & $\mathrm{a}[\mathrm{m}]$ & 0.5 \\
\hline$\lambda$ & $\operatorname{diag}(3,3,5)$ & $\mathrm{b}[\mathrm{m}]$ & 0.5 \\
\hline $\boldsymbol{\tau}_{\max }[\mathrm{Nm}]$ & 1.5 & $\mathrm{c}[\mathrm{m}]$ & 0.05 \\
\hline $\boldsymbol{\tau}_{\min }[\mathrm{Nm}]$ & 0 & $\mathrm{~d}[\mathrm{~m}]$ & 0.04 \\
\hline \multicolumn{3}{|c|}{ Dinamik parametreler } \\
\hline$\tau_{f}[\mathrm{Nm}]$ & $\operatorname{diag}(0.05,0.05,0.05,0.05)$ & $\boldsymbol{F}_{R}[\mathrm{~N}]$ & $\mathbf{0}$ \\
\hline$I_{e}\left[\mathrm{kgm}^{2}\right]$ & $1.667^{*} 10^{-3}$ & $\boldsymbol{M}_{R}[\mathrm{Nm}]$ & $\mathbf{0}$ \\
\hline$J[\mathrm{Nm}]$ & $\operatorname{diag}(2.2,2.2,2.2,2.2)^{*} 10^{-4}$ & $r_{[m}[\mathrm{m}]$ & 0.05 \\
\hline $\boldsymbol{C}[\mathrm{Nm}]$ & $\operatorname{diag}(0.07,0.07,0.07,0.07)$ & $m_{e}[\mathrm{~kg}]$ & 1 \\
\hline
\end{tabular}

Kablo uzunluklarını kullanarak ileri kinematiği çözmek için YSA ve Newton-Raphson yöntemi sıralı kullanılmıştır. YSA'dan gelen ileri kinematik çözümü, Newton-Raphson yöntemine bir başlangıç koşulu olarak verilmiştir. Newton-Raphson yönteminin çıktısı, KSPR'nin gerçek konumu ve yönelimi olarak denetim sistemine geri beslenmiştir. Son olarak nihai denetim giriş torkunu belirlemek için kayan kipli denetim yöntemi ve pozitif gerilmeleri sağlayan gerilim dağıtım algoritması uygulanmıştır.

Uç işlemcinin verilen yörüngeyi izleme başarımını test etmek için ilk olarak yönelimi sıfır olacak şekilde $(x, y)$ düzleminde dairesel bir yörünge seçilmiştir. Benzetim için seçilen yörünge ile birçok gerçek uygulamaya benzer olarak uç işlemcinin herhangi bir dönme olmadan istenilen $x, y$ koordinatlarında konumlandırılması test edilmiştir. İstenen yörüngenin izlenmesine dair benzetim sonuçları Şekil 6a'da verilmiştir. Şekilde görüldüğü üzere, kayan kipli denetleyici KSPR sisteminin istenen yörüngeyi izlemesinde başarılı sonuç göstermiştir. Kayan kipli denetleyicinin ulaşma ve kayma aşamalarını görmek için uç işlemcinin harekete başlangıç koşulları yörünge başlangıç değerlerinden farklı olarak tanımlanmıştır. 

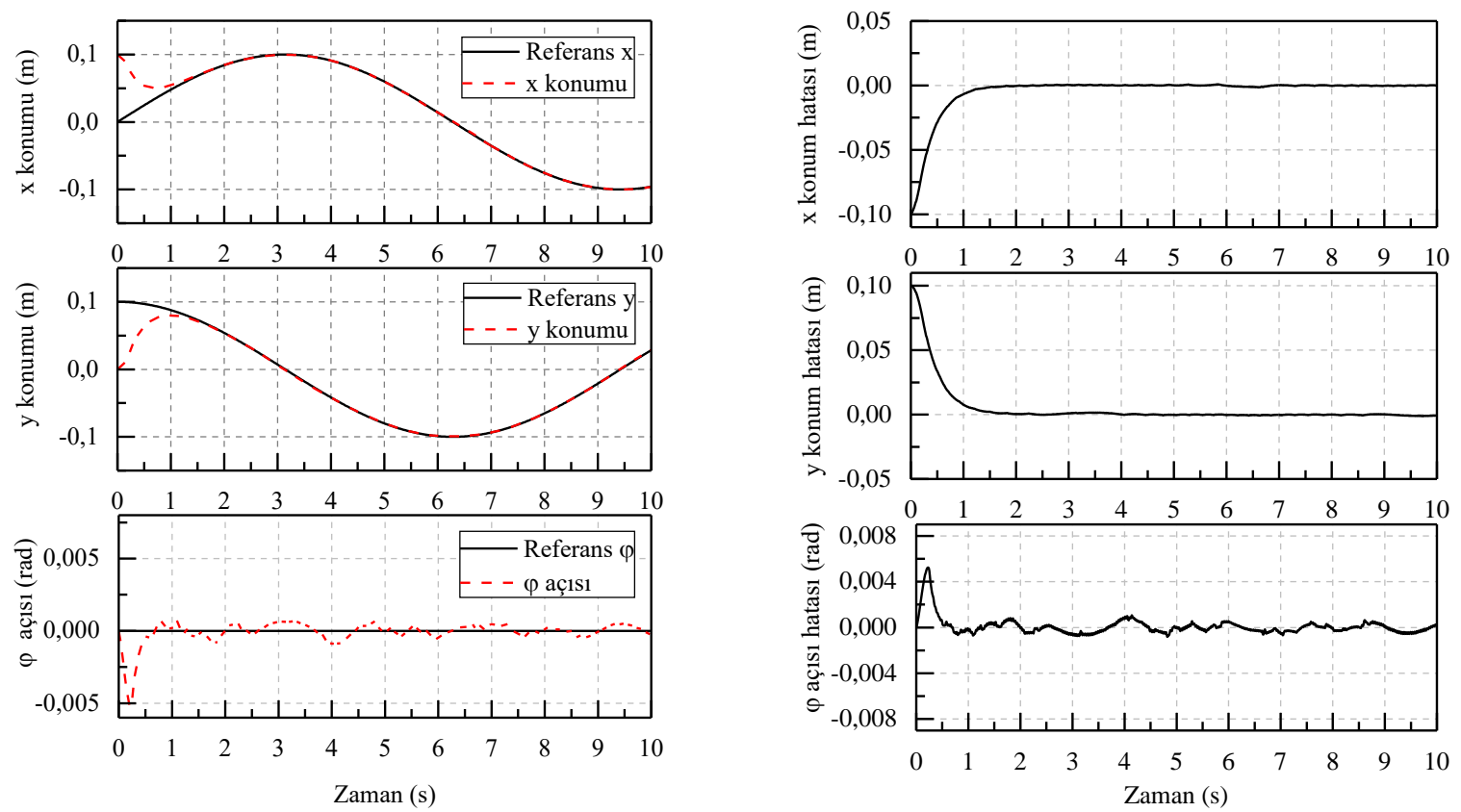

Şekil 6. a) Dairesel yörünge takibi için $x, y$ konumu ve $\varphi$ açısı cevabı (solda) b) Referans verilen yol ile uç işlemcinin izlediği yol arasındaki hata (sağda)

Figure 6. a) Desired trajectory and actual trajectory of the circular motion w.r.t. time (left) b) Tracking errors (right)

KSPR'nin gerçek konumu bir saniye içinde istenen yörüngeye ulaşmış ve ulaşma aşamasından sonra da başarılı bir şekilde referans girdisini izlemiştir. Denetim sonucunda kalıcı durum kök ortalama kare hataları (root mean square error, RMSE) $x$, y ve $\phi$ için sırasıyla, $0.0156,0.0170,7.69 \times 10^{-4}$ olarak belirlenmiştir. Ayrıca Şekil 6b'de yörüngeye ait izleme hataları gösterilmektedir. Bir diğer benzetim çalışmasında ise $\phi$ açısı referansının sinüzoidal olduğu durumda kontrolcü başarımı test edilmiştir. Referans açısı olarak 0.05 rad genlikli sinüs sinyali seçilmiştir. Bu değer uç işlemcinin ulaşabileceği maksimum açı değerinin yarısıdır. Bu durumdaki denetim cevabı ise Şekil 7 'de verilmektedir. $x, y$ ve $\phi$ için RMSE hataları sırası ile $0.0156,0.0170$ ve 0.0109 olarak bulunmuştur. Denetim başarımlarından anlaşılacağı üzere farklı açı değerleri için $\mathrm{x}$, y konumu da dahil benzer başarımlar elde edilmiştir. Tasarlanan kontrolcü farklı referans girdileri için hassas ve kararlı bir denetim sunmaktadır. Bu durumun desteklenmesi için basamak cevabı benzetimleri de yapılmıştır. Referans girdisi olarak $(\mathrm{x}, \mathrm{y})$ koordinatlarında $(0.1,0.1) \mathrm{m}$ genlikli basamak girdisi uygulanmıştır. Denetim cevabı için başarım değerleri; yükselme zamanı $\left(t_{r}\right)$, yerleşme zamanı $\left(t_{s}\right)$ ve kalıcı durum hatası $(e)$ sırasıyla $0.8 \mathrm{~s}, 1.54 \mathrm{~s}$, $4.39 \times 10^{-4} \mathrm{~m}$ olarak bulunmuştur. ( $\left.\mathrm{x}, \mathrm{y}\right)$ koordinatlarında daha iyi bir görselleştirme açısından sıfır başlangıç koşullarına sahip olan uç işlemcinin dairesel yörünge takibi Şekil 8a' da (x,y) düzlemi üzerinde gösterilmiştir. Son olarak karma yöntemin doğruluğunun belirlenmesi için, elde edilen ileri kinematik çözümüne ait robot konumları ile dinamik sistemin benzetim ortamındaki gerçek konumu arasındaki hata Şekil 8b'de gösterilmiştir. 

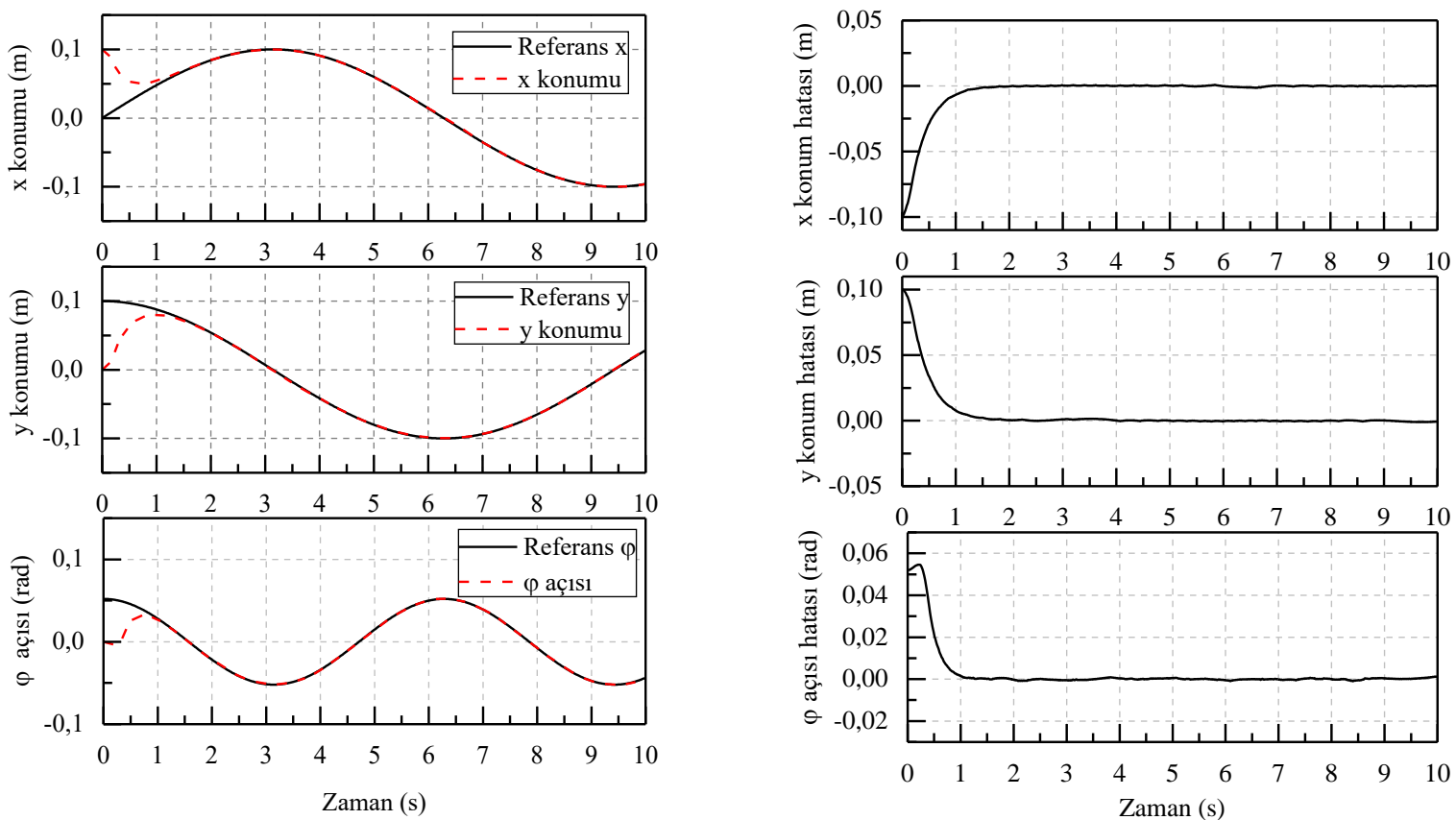

Şekil 7. a) x, y ve $\varphi$ referans takibi (solda) b) Referans verilen yol ile uç işlemcinin izlediği yol arasındaki hata (sağda)

Figure 5. a) Trajectory tracking of $x, y$ and $\varphi$ reference (left) b) Tracking errors (right)
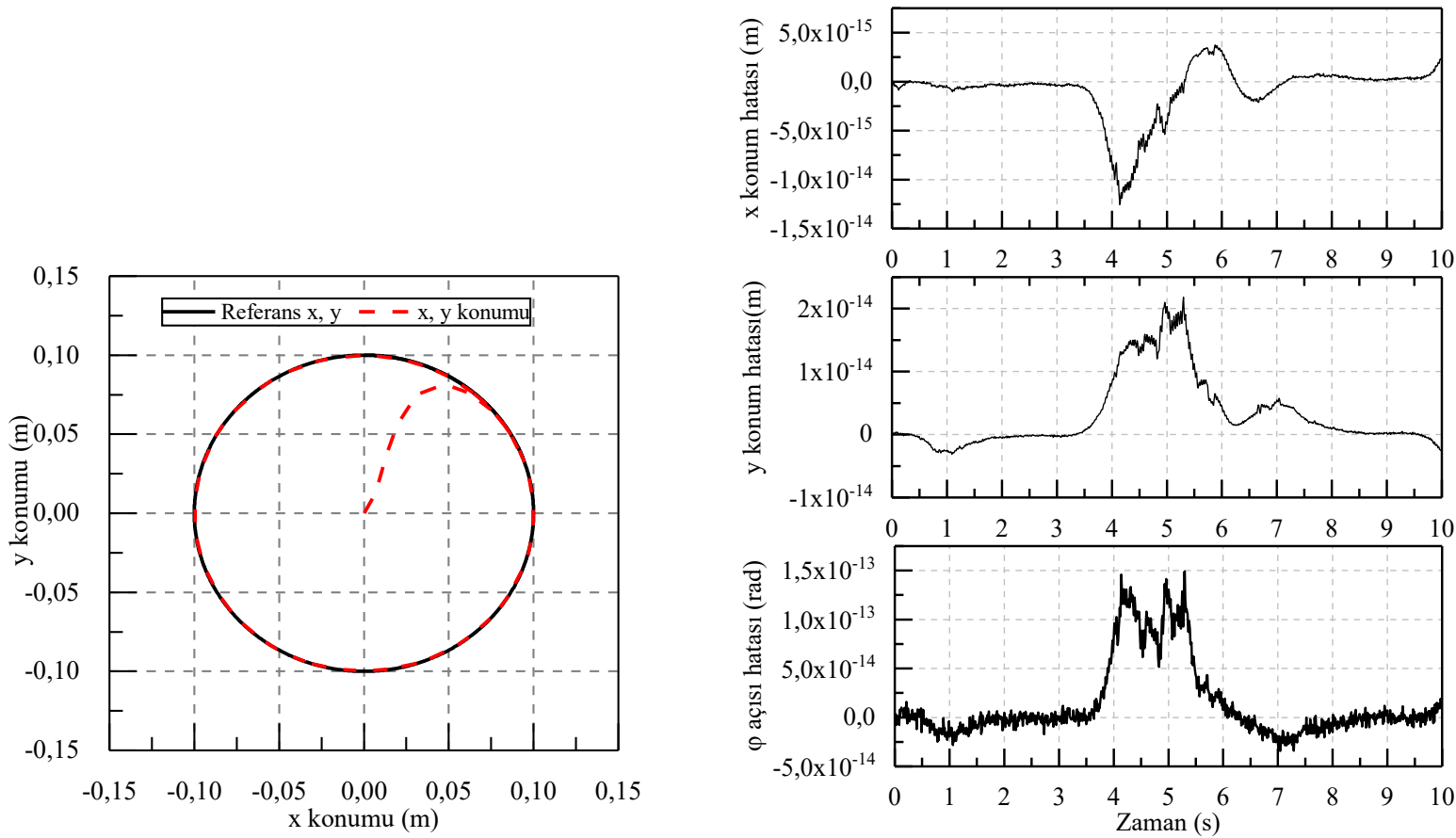

Şekil 8. a) Uç işlemciye takip ettirilen dairesel yörünge (solda) b) Gerçek konum ve karma yöntemden elde edilen konum arasındaki hata(sağda)

Figure 8. a) Circular trajectory tracking (left) b) The error between actual pose and hybrid forward kinematics solution (right)

Çizelge 2'de $\mathrm{x}$, y ve $\phi$ parametrelerine ait kök ortalama kare hataları (RMSE) yalnızca YSA modelinin kullanıldığı durum, yalnız Newton-Raphson yönteminin kullanıldığ1 durum ve karma yöntemin kullanıldığı durum için karşılaştırılmıştır. Sadece sayısal yöntem kullanılarak elde edilen sonuçlarda yakınsamama durumu gerçekleştiği için iterasyon limiti olan 50 iterasyon tamamlanmış ve 
sonuçlar yüksek hatalı çıkmıştır. Karma yöntemde ise iki iterasyon sonunda çok düşük hata payı ile hızlı ve doğru çözümler elde edilmiştir. Karma yöntem kullanıldığında iki iterasyon ile hatanın büyük ölçüde azaltılması bu yöntemin işlem yükünün düşük olduğunu göstermektedir. Hatayı daha da azaltmak için Newton-Raphson yönteminde iterasyon durdurma şartı olan $\varepsilon<10^{-4}$ parametresinin değiştirilmesiyle iterasyon sayısını arttırmak mümkündür ancak iterasyon sayısı arttığında işlem süresi uzamaktadır. Bu nedenle iki işlem arasındaki dengeyi sağlamak önemlidir.

Çizelge 2. Kök Ortalama Kare Hataları

Table 2. Root Means Square Error (RMSE)

\begin{tabular}{|l|l|l|l|}
\hline Yöntem / Parametre & $\mathrm{x}(\mathrm{m})$ & $\mathrm{y}(\mathrm{m})$ & $\phi(\mathrm{rad})$ \\
\hline YSA & $2.40 \times 10^{-4}$ & $3.73 \times 10^{-4}$ & $2.68 \times 10^{-4}$ \\
\hline YSA+Newton Raphson & $2.85 \times 10^{-15}$ & $6.44 \times 10^{-15}$ & $4.13 \times 10^{-14}$ \\
\hline
\end{tabular}

\section{SONUÇLAR (RESULTS)}

Bu çalışmada, dört kablo ile sürülen düzlemsel paralel bir robotun ileri kinematiği ve yörünge izleme denetimi ele alınmıştır. İleri kinematik problemini çözmek için kablo uzunluklarını kullanarak uç işlemcinin konumunu veren bir karma yöntem kullanılmıştır. Karma yöntem farklı paralel manipülatörlere uygulanabilen bir yöntem olup, Yapay Sinir Ağları ve Newton-Raphson yönteminin ardışık kullanımına dayanmaktadır (Parikh ve Lam, 2005). Benzetim sonuçları, karma yöntemin doğru sonuca yakınsamasının tek başına YSA veya Newton-Raphson yönteminden daha iyi olduğunu göstermektedir. İleri kinematiğin çözümünde sadece YSA kullanılması iyi sonuçlar ortaya çıkarmaktadır. Fakat çok hassas bir sonuç için YSA eğitiminde kullanılan veri setinin çok fazla olması, parametrelerinin iyi ayarlanması ve ağın eğitimi için orantılı olarak daha fazla süre gerekmektedir. Bu durum, yöntemin kablolu robotlar için gerçek zamanlı uygulamalarda pratik olarak uygulanması açısından sorun oluşturacaktır. Başlangıç koşullarından bağımsız olarak gerçek çözüme yakınsama için geliştirilmiş genel (global) yakınsayan Newton-Raphson yöntemleri kullanılabilir (Flannery ve diğ., 1992). Fakat rastgele seçilmiş başlangıç şartları gerçek çözüme yakınsama için gerekli olan iterasyon sayısını ve dolayısıyla hesaplama süresini artırmaktadır. Bu nedenle genel yakınsayan yöntemlerin gerçek zamanlı uygulamalarda tek başlarına kullanılması kısıtlıdır. Kullanılan karma yöntemde hesaplama yükünün düşük olması ve kısa sürede çözüme ulaşılması, yöntemin gerçek uygulamalarda kullanılabilirliğini desteklemektedir. Elde edilen sonuçlar, kablolu düzlemsel bir manipülatörde istenen bir yörüngeyi doğru ve hassas bir şekilde izlemek için kayan kipli denetleyicinin karma ileri kinematik çözüm yöntemi ile birlikte başarıyla uygulayabildiğini göstermektedir. Gelecekteki bir çalışma olarak, bu yöntemler bütünü deneysel olarak uygulanacaktır.

\section{TEŞEKKÜR (ACKNOWLEDGMENT)}

Bu çalışma Karadeniz Teknik Üniversitesi Bilimsel Araştırma Projeleri Koordinasyon Birimince FBA-2018-7415 numaralı proje kapsamında desteklenmiştir. Destekleri için Karadeniz Teknik Üniversitesi'ne teşekkür ederiz.

\section{KAYNAKLAR (REFERENCES)}

Bayani, H., Masouleh, M. T., Kalhor A., 2016, "An experimental study on the vision-based control and identification of planar cable-driven parallel robots", Robotics and Autonomous Systems, Cilt 75, ss. $187-202$.

Bosscher, P., Williams II, R. L., Bryson, L. S., Castro-Lacouture, D., 2007, “Cable-suspended robotic contour crafting system", Automation in construction, Cilt 17, Sayı 1, ss. 45-55.

Flannery, B. P., Press, W. H., Teukolsky, S. A., Vetterling, W., 1992, Numerical recipes in C. Press Syndicate of the University of Cambridge, New York. 
Ghasemi, A., Eghtesad, M., Farid, M., 2010, “Neural network solution for forward kinematics problem of cable robots", Journal of Intelligent \& Robotic Systems, Cilt 60, No 2, ss. 201-215.

Gosselin, C., 2014, "Cable-driven parallel mechanisms: state of the art and perspectives", Mechanical Engineering Reviews, Cilt 1, Say1 1, ss. DSM0004-DSM0004.

Jeong, J. W., Kim, S. H., Kwak, Y. K., 1999, "Kinematics and workspace analysis of a parallel wire mechanism for measuring a robot pose", Mechanism and Machine Theory, Cilt 34, Sayı 6, ss. 825841.

Khosravi, M. A., Taghirad, H. D., 2014, “Robust PID control of fully-constrained cable driven parallel robots", Mechatronics, Cilt 24, Say1 2, ss. 87-97.

Lv, W., Tao, L., Hu, Y., 2017, “On the real-time calculation of the forward kinematics of a suspended cable-driven parallel mechanism with 6-degree-of-freedom wave compensation", Advances in Mechanical Engineering, Cilt 9, No 6. ss. 1687814017706264.

Lv, W., Tao, L., Ji, Z., 2017, "Sliding mode control of cable-driven redundancy parallel robot with 6 DOF based on cable-length sensor feedback", Mathematical Problems in Engineering.

Lytle, A. M., Saidi, K. S., Bostelman, R. V., Stone, W. C., Scott, N. A., 2004, "Adapting a teleoperated device for autonomous control using three-dimensional positioning sensors: experiences with the NIST RoboCrane." Automation in Construction, Cilt 13, No 1, ss. 101-118,.

Merlet, J. P., 2006, Parallel robots, Cilt 128, Springer Science \& Business Media.

Oh, S. R. ve Agrawal, S. K., 2004, "Nonlinear sliding mode control and feasible workspace analysis for a cable suspended robot with input constraints and disturbances", Proceedings of the 2004 American Control Conference, Boston, Cilt 5, ss. 4631-4636.

Parikh, P. J. ve Lam, S. S., 2005, "A hybrid strategy to solve the forward kinematics problem in parallel manipulators." IEEE Transactions on Robotics, Cilt 21 No 1, ss. 18-25.

Pott, A., 2010, "An algorithm for real-time forward kinematics of cable-driven parallel robots", Advances in Robot Kinematics: Motion in Man and Machine, Editör: Lenarcic J., Stanisic M., Springer, Dordrecht, ss. 529-538.

Pott, A., Schmidt, V., 2015, “On the forward kinematics of cable-driven parallel robots", 2015 IEEE/RSJ International Conference on Intelligent Robots and Systems (IROS), Hamburg, ss. 3182-3187.

Sancak C., Yamaç F., İtik M., 2018, "Kablo ile Sürülen Düzlemsel Paralel Bir Robotun Tasarımı ve Kontrolü", TOK2018 Otomatik Kontrol Ulusal Toplantısl, Kayseri, ,s.367-371.

Schmidt, V., Müller, B., Pott, A., 2014, "Solving the forward kinematics of cable-driven parallel robots with neural networks and interval arithmetic", Computational Kinematics, Cilt 15, Editör: Thomas F., Perez Gracia A., Mechanisms and Machine Science, Springer, Dordrecht, ss. 103110.

Shen, Y., Osumi H. ve Arai, T., 1994, "Manipulability measures for multi-wire driven parallel mechanisms", Proceedings of 1994 IEEE International Conference on Industrial Technology-ICIT'94, Guangzhou, ss. 550-554.

Vadia, J., 2003, Planar cable direct driven robot: Hardware implementation, Doktora Tezi, Ohio Universitesi.

Williams, R. L., Gallina, P., Vadia, J., 2003, "Planar Translational Cable-Direct-Driven Robots", Journal of Field Robotics, Cilt 20, No 3, ss. 107-120. 